\title{
Genotype $\times$ nutrient association of common polymorphisms in obesity-related genes with food preferences and time structure of energy intake
}

\author{
Julie Bienertová-Vašků ${ }^{1}$, Petr Bienert ${ }^{1}$, Martin Forejt ${ }^{2}$, Josef Tomandl ${ }^{3}$, Zuzana Brázdová ${ }^{2}$ \\ and Anna Vašků ${ }^{1}$ \\ ${ }^{1}$ Institute of Pathological Physiology, Medical Faculty, Masaryk University, Kamenice 5, Brno 625 00, Czech Republic \\ ${ }^{2}$ Department of Preventive Medicine, Faculty of Medicine, Masaryk University, Tomesova 12, Brno 602 00, Czech Republic \\ ${ }^{3}$ Department of Biochemistry, Faculty of Medicine, Masaryk University, Kamenice 5, Brno 625 00, Czech Republic
}

(Received 9 March 2009 - Revised 25 June 2009 - Accepted 7 August 2009 - First published online 14 September 2009)

Personal food preferences can either enhance or suppress the development of obesity and the selection and proportion of macronutrients in the diet seem to have a heritable component. In the present study, we therefore focused on dietary composition as a specific trait related to obesity and we determined whether genetic variations in leptin (LEP), LEP receptor (LEPR), adiponectin (ADIPOQ), IL-6 and pro-opiomelanocortin (POMC) underlie specific native food preferences and obesity-related anthropometric parameters. The total of 409 individuals of Czech Caucasian origin were enrolled into the present study and $7 \mathrm{~d}$ food records were obtained from the study subjects along with selected anthropometric measurements. In a subset of study subjects, plasma levels of ADIPOQ, LEP and soluble LEPR were measured. Independently of the BMI of the individuals, common variations in LEP and LEPR genes were associated with specific eating patterns, mainly with respect to timing of eating. The LEP +19 A/G polymorphism served as an independent predictor for BMI, percentage of body fat and skinfold thickness and significantly affected the time structure of the daily energy intake. The POMC Rsa I polymorphism was associated with percentage of body fat. The ADIPOQ $45 \mathrm{~T} / \mathrm{G}$ polymorphism was associated with the thickness of the subscapular skinfold. The LEPR Gln223Arg polymorphism was associated with multiple parameters, including diastolic blood pressure, meal sizes during the day and plasma ADIPOQ levels. In a separate analysis, soluble leptin receptor (sObR) plasma levels and LEP:sObR ratio were significantly correlated with systolic blood pressure ( $\beta=-0.66, P=0.002 ; \beta=-1 \cdot 23, P=0.02)$ and sObR plasma levels also served as an independent predictor for diastolic blood pressure $(\beta=-0.50 ; P=0.04)$. To conclude, we report common allelic variants associated with specific feeding behaviour and obesity-related anthropometric traits. Moreover, we identified allelic variants that significantly influence the time structure of food intake during the day.

Adipokines: Polymorphisms: Obesity: Nutrition: Feeding behaviour

In Western societies, the prevalence of obesity has been steadily increasing for the last few decades. Obesity (Online Mendelian Inheritance in $\mathrm{Man}^{\circledR}$ (OMIM) no. 601665) is generally associated with an increased risk for cardiovascular disorders, diabetes, lipid disorders and some types of cancer. The disease is generally associated with specific lifestyle and dietary habits that interfere with the given genetic background of the individual and several studies have focused recently on the genetic background of these characteristics ${ }^{(1,2)}$. However, resolution of the genetic factors underlying the susceptibility to certain feeding or lifestyle behaviour is far from being completed.

Previously, various studies reported a heritable component for specific feeding behaviour ${ }^{(3-8)}$. However, the underlying mechanisms that could explain credibly the inheritance of food preferences are yet to be elucidated. Various adipokines and their genetic variability have been found to be associated with obesity and its related traits; however, the results are often contradictory ${ }^{(9-13)}$.
Recently, it has been reported by de Krom et al. ${ }^{(14)}$ that certain common allelic variants in leptin (LEP) and LEP receptor (LEPR) genes are specifically associated with distinctly different eating patterns, namely extreme snacking behaviour or excessive portion size ${ }^{(14)}$. On the other hand, Schulz et al. ${ }^{(15)}$ propose strong evidence for lifestyle-based, i.e. environmental, influences based on their observations of Pima Indians and they suggest that the lifestyle associated with Westernisation plays a major role in the global epidemic of type 2 diabetes, independently of genetic background of an individual $^{(15)}$.

Although it has been reported that genetic variations underlie specific eating patterns ${ }^{(4)}$ and that specific food preferences are considered to be a risk factor for obesity, only a few reports have focused on these genotype $\times$ nutrient associations ${ }^{(16)}$, and none has examined thoroughly the relationship between the single nucleotide polymorphisms (SNP) in genes encoding for adipokines and the time structure of the daily energy intake.

Abbreviations: ADIPOQ, adiponectin; LEP, leptin; LEPR, leptin receptor; POMC, pro-opiomelanocortin; SNP, single nucleotide polymorphism; sObR, soluble leptin receptor.

* Corresponding author: Dr Julie Bienertová-Vašků, fax +420 549494340, email jbienert@med.muni.cz 
Our previous study on 185 healthy Caucasian volunteers of Middle-European origin did not reveal any significant associations of selected SNP in LEP, LEPR, adiponectin (ADIPOQ), pro-opiomelanocortin (POMC) and ghrelin genes with specific food behaviour. However, in further analyses, distinct trends were observed towards specific nutritional behaviour and therefore the cohort sample was substantially extended for the purposes of the present study.

The aim of the present case-control study on 409 unrelated individuals of Czech (middle-European) Caucasian origin was to analyse the possible associations of eight selected SNP in obesity-related genes with selected lifestyle and dietary characteristics of studied individuals.

\section{Experimental methods}

\section{Study subjects}

A total of 409 unrelated Czech Caucasian individuals were recruited for the present study in a mass media campaign addressing the population of the south Moravia region of the Czech Republic ${ }^{(17)}$. The participants were divided into two groups: obese and lean subjects. The inclusion and exclusion criteria were derived from Ma et al. ${ }^{(18)}$. The present study was conducted according to the guidelines laid down in the Declaration of Helsinki and all procedures involving human subjects were approved by the Committee for Ethics of Medical Experiments on Human Subjects, Faculty of Medicine at Masaryk University (Brno, Czech Republic). Written informed consent was obtained from all subjects and it was archived.

The first subgroup consisted of 252 obese individuals (BMI $\geq 30 \mathrm{~kg} / \mathrm{m}^{2}$; mean BMI 37.4 (SD 6.25) $\mathrm{kg} / \mathrm{m}^{2}$; median age 49.1 years; age range 18.6-73.9 years). The control group consisted of 157 healthy normal-weight control subjects with no history of childhood obesity or eating disorder (mean BMI 25.2 (SD 3.1$) \mathrm{kg} / \mathrm{m}^{2}$; median age 37.1 years; age range $18 \cdot 1-67.5$ years). A set of sixty-four morbidly obese patients was selected from the obese group (BMI $\geq 40 \mathrm{~kg} / \mathrm{m}^{2}$; mean BMI 45.5 (SD 5.6$) \mathrm{kg} / \mathrm{m}^{2}$; median age 52.4 years; age range 18.6-73.2 years). These individuals were available for plasma LEP, soluble LEPR (sObR) and ADIPOQ analyses and were precisely matched for age and sex with another sixty-four subjects (control or non-morbidly obese) that underwent the same set of biochemical analyses.

\section{Anthropometric characteristics}

All phenotypic measurements were performed by three specialists and included weight, height, BMI, lean body mass, fat mass, body fat, waist and hip circumferences, waist: hip ratio and skinfold thickness. Body composition was assessed by bioelectrical impedance analysis, using the single frequency bioimpedance analyser (BodyStat Ltd, Douglas, Isle of Man, UK), with the subject lying in a supine position. The measurement of height was performed with a calibrated stadiometer and weight (in light indoor clothes and without shoes) was measured with a precisely calibrated set of scales.

\section{Dietary intake}

Participants were furthermore advised to complete standardised $7 \mathrm{~d}$ food records. Food intake data were obtained from the study subjects and were further analysed, whereas the percentage of daily energy intake from carbohydrates, fat and protein as well as total energy and macronutrient intake were calculated using the Nutrimaster Diet Analysis software modified for the Czech population (Abbott Laboratories, Abbott Park, IL, USA). Special attention was paid to extreme snacking behaviour (defined as higher daily energy intake from snacks than $25 \%$ ), eventual dieting, extreme portion sizes and irregularity in eating. The structure of the daily energy intake was also investigated - a snacking index (established as a ratio of daily energy intake from snacks $v$. daily energy intake from the main meals) was calculated.

\section{Candidate genes}

The selection of particular SNP was based on: (1) population frequency in the European Caucasian population; (2) their known or potential functional or regulatory impact on feeding behaviour or association in the case of synonymous SNP; and/or (3) a previously described association with obesity or feeding behaviour.

Genotyping was carried out for eight SNP in five genes related to the production of adipokines, control of energy homeostasis, appetite and satiety regulation: LEP (rs2167270); LEPR (rs1137101); ADIPOQ (rs2241766, + 94T/G); IL-6 (rs1800797, rs1800795); POMC (rs3754860, rs1009388).

\section{Genotyping}

DNA for analyses was extracted from $5 \mathrm{ml}$ of the patients' saliva using a standard technique employing proteinase K. Genotyping of each of eight investigated SNP in ADIPOQ, LEP, LEPR, IL6 and POMC genes was performed as described previously ${ }^{(19-26)}$, using standard PCR-based methodology followed by restriction fragment length polymorphism with subsequent electrophoresis on the agarose gel with ethidium bromide staining. The DNA fragments were visualised by UV illumination using Image Analyser (AlphaImager $^{\text {TM }}$ 1220; Alpha Innotech Corp., San Leandro, CA, USA).

All reactions were performed using the XP BIOER Cycler (Bioer Technology Co. Ltd, Hangzhou, China), the overall genotyping success varied between $83.3 \%$ (LEP +19A/G) and $99.7 \%$ (LEPR Gln223Arg); missing genotypes were due to either consistent PCR dropout or depletion of template DNA. To assess genotyping reliability we performed double sampling in more than $20 \%$ of the samples and found no differences. We always used quality control and negative controls were used to identify possible false-positives.

\section{Determination of plasma leptin, soluble leptin receptor and adiponectin}

Blood samples for total LEP, ADIPOQ and sObR plasma analyses were collected after overnight fasting and were immediately centrifuged at $1700 \mathrm{~g}$ for $20 \mathrm{~min}$ and then stored at $-80^{\circ} \mathrm{C}$ until analysis. Plasma LEP and sObR levels were 
measured by commercially available sandwich ELISA (R\&D Systems, Minneapolis, MN, USA) with a sensitivity of $7.8 \mathrm{pg} / \mathrm{ml}$ and $0.057 \mathrm{ng} / \mathrm{ml}$, respectively. Plasma samples for LEP and sObR were 100-fold and 5-fold diluted with calibrator diluent immediately before the assay, respectively. The intraand inter-assay $\mathrm{CV}$ were less than 3.3 and $5.4 \%$ for the LEP assay, and 6.1 and $8.6 \%$ for the sObR assay, respectively. Plasma ADIPOQ levels were measured by a commercially available ELISA (RayBiotech, Norcross, GA, USA) with a sensitivity less than $10 \mathrm{pg} / \mathrm{ml}$. Samples were 50000 -fold diluted in singlet to assay range $(4 \cdot 1-1000 \mathrm{pg} / \mathrm{ml})$ with standardised assay diluent. The intra- and inter-assay $\mathrm{CV}$ were less than 10 and $12 \%$, respectively.

\section{Statistics}

The genotype distributions were tested for Hardy-Weinberg equilibrium by a set of $\chi^{2}$ tests. Allelic frequencies were estimated by the 'counting method' and differences in allele frequencies between case and control subjects were tested by likelihood ratio $\chi^{2}$ tests for $2 \times 2$ tables (two alleles, case $v$. control subjects). Where applicable, it was first determined whether the variable presented a normal distribution using the Kolmogorov-Smirnov test, and in cases of skewed variables, logarithmic transformation was performed. For descriptive purposes, mean values are presented using untransformed values. Results are expressed as mean values and standard deviations unless otherwise stated.

To identify genetic as well as non-genetic variables that may contribute to predicting the anthropometric phenotype or nutritional phenotype, we carried out a forward stepwise logistic regression, a sequential procedure of adding one input variable at a time to build up a regression model in which the dependent variable (i.e. presence or absence of obesity) is represented as the linear combination of independent variables (anthropometric and nutritional parameters and genotypes of eight investigated SNP). In this analysis, the codes of genotypes were used as quantitative variables $(\mathrm{AA}=0, \mathrm{AB}=1, \mathrm{BB}=2)$.

OR were calculated using the multiple logistic regression analysis models; we adjusted for covariates including age (continuous), BMI (<23, 23-24.9, 25-29.9, 30-34.9, or $\geq 35 \mathrm{~kg} / \mathrm{m}^{2}$ ), sex, smoking (never, past, and current), alcohol intake (non-drinker and drinker $(0 \cdot 1-4 \cdot 9,5-10$, or $>10 \mathrm{~g} / \mathrm{d})$ ), family history of obesity and menopausal status in females.

Using sample tertiles, the nutrient variables were categorised in three groups of equal size (the upper third, the middle third and the lower third) as described by Santos et al. ${ }^{(16)}$. Each nutrient variable was then included in logistic regressions as binary indicators leaving one category as the reference.

The data analysis was performed using the Statistica v. 8.0 (Statsoft Inc., Tulsa, OK, USA) program package. The values of $P<0.05$ were considered statistically significant.

\section{Results}

The baseline demographic, anthropometric, dietary and clinical characteristics of the study subjects in relation to sex are listed in Table 1. The allele frequencies of all examined
SNP exceeded 0.05. The Hardy-Weinberg equilibrium test showed that the examined polymorphisms, except for the ADIPOQ 45T/G and ADIPOQ 94T/G polymorphisms in the obese group, were in Hardy-Weinberg equilibrium. Moreover, no significant differences both in genotype distributions and allele frequencies were observed when comparing the morbidly obese cohort $\left(\mathrm{BMI}>40 \mathrm{~kg} / \mathrm{m}^{2}\right)$ with the controls and the obese cohort $\left(30<\mathrm{BMI} \leq 40 \mathrm{~kg} / \mathrm{m}^{2}\right)$ with the controls $\left(\mathrm{BMI} \leq 30 \mathrm{~kg} / \mathrm{m}^{2}\right)$ (Table 2$)$.

Effect of single nucleotide polymorphisms on anthropometric characteristics (BMI, waist:hip ratio, total body fat, skinfold thickness)

In the next step, we tested whether these SNP had any effect on anthropometric characteristics related to obesity in the study subjects.

Univariate logistic regression analysis revealed that the subjects with the GG genotype of LEP $+19 \mathrm{~A} / \mathrm{G}$ had a 1.9 higher risk for the development of obesity compared with subjects with the LEP +19 A allele (OR 1.9 (95\% CI 0.87, 3.02); $P=0.002$ ). Moreover, the AA homozygotes of the LEPR Gln223Arg polymorphism carried in the univariate analysis approximately half the risk for the development of increased diastolic blood pressure when compared with the $\mathrm{G}$ allele carriers (OR 0.49 (95\% CI 0.12, 1.32); $P=0.002)$. In the multivariate regression modelling across all the study subjects that was based on the results of the univariate analysis, the LEP + 19A/G polymorphism expressed an independent prediction role for BMI $(\beta=-0.15 ; P=0.02)$, while LEPR Gln223Arg was significantly correlated with diastolic blood pressure $(\beta=-0.15 ; P=0.02)$. When analysing the possible relationships between the SNP and the thickness of the skinfolds, LEP $+19 \mathrm{~A} / \mathrm{G}$ expressed a significant prediction role for the thickness of the triceptal skinfold $(\beta=-0 \cdot 14$; $P=0.04)$ and ADIPOQ $+94 \mathrm{~T} / \mathrm{G}$ was correlated with the thickness of the subscapular skinfold $(\beta=0.13 ; P=0.04)$. Moreover, LEP + 19A/G and POMC Rsa I expressed an independent prediction role for percentage of body fat in the multivariate analysis $(\beta=-0.17, P=0.008 ; \beta=0.13 ; \beta=0.13$, $P=0 \cdot 03$, respectively).

\section{Effect of single nucleotide polymorphisms on dietary characteristics and food preferences of the study subjects}

In the univariate regression modelling, none of the examined polymorphisms served as an independent predictor for percentage of daily energy intake from macronutrients or abnormal eating patterns (extreme snacking behaviour, extreme portion sizes, night eating, irregular food intake; NS). When analysing the general eating behaviour patterns in the tertile analysis, the presence of extreme snacking behaviour was in the total studied cohort (obese plus non-obese individuals) associated with lower obesity risk (Table 3). This effect was also observed in females separately (OR 0.42 (95\% CI 0.23 , 0.77 ); $P=0.003$ ), but not in males (OR 1.26 (95\% CI 0.42 , $3.74) ; P=0.44)$.

When analysing the distribution of energy intake during the day, the ADIPOQ $+45 \mathrm{~T} / \mathrm{G}$ polymorphism was in the univariate regression modelling associated with the energy value of breakfast, defined as the first meal during the day $(\beta=0 \cdot 15$; 
Table 1. Descriptive statistics of the patients' baseline characteristics (Mean values and standard deviations)

\begin{tabular}{|c|c|c|c|c|c|c|c|c|c|c|c|c|}
\hline \multirow[t]{3}{*}{ Group... } & \multicolumn{4}{|c|}{ Obese ( $n$ 252) } & \multicolumn{4}{|c|}{ Morbidly obese $(n 64)^{\star}$} & \multicolumn{4}{|c|}{ Controls ( $n$ 157) } \\
\hline & \multicolumn{2}{|c|}{ Female } & \multicolumn{2}{|c|}{ Males } & \multicolumn{2}{|c|}{ Females } & \multicolumn{2}{|c|}{ Males } & \multicolumn{2}{|c|}{ Females } & \multicolumn{2}{|c|}{ Males } \\
\hline & Mean & SD & Mean & SD & Mean & SD & Mean & SD & Mean & SD & Mean & SD \\
\hline Subjects $(n)$ & \multicolumn{2}{|c|}{188} & \multicolumn{2}{|c|}{64} & \multicolumn{2}{|c|}{51} & \multicolumn{2}{|c|}{13} & \multicolumn{2}{|c|}{120} & \multirow{2}{*}{\multicolumn{2}{|c|}{37}} \\
\hline Body composition & & & & & & & & & & & & \\
\hline Age (years) & $50 \cdot 1$ & 11.4 & $46 \cdot 4$ & $12 \cdot 2$ & $51 \cdot 6$ & $10 \cdot 6$ & $48 \cdot 7$ & $13 \cdot 0$ & 38.8 & $13 \cdot 2$ & $36 \cdot 8$ & $14 \cdot 0$ \\
\hline $\mathrm{BMI}\left(\mathrm{kg} / \mathrm{m}^{2}\right)$ & 37.5 & $6 \cdot 3$ & 37.0 & 6.0 & $45 \cdot 3$ & $5 \cdot 2$ & 46.9 & $5 \cdot 3$ & $25 \cdot 0$ & $3 \cdot 3$ & 25.7 & 2.5 \\
\hline Body fat (\%) & $46 \cdot 3$ & 5.9 & $32 \cdot 8$ & 6.7 & $52 \cdot 4$ & $4 \cdot 1$ & 41.9 & 3.8 & 31.5 & $7 \cdot 0$ & 19.5 & $6 \cdot 0$ \\
\hline \multicolumn{13}{|l|}{ Dietary intake } \\
\hline Energy (kJ) & 7848 & 2410 & 10791 & 3201 & 7344 & 1885 & 10357 & 3394 & 7799 & 1768 & 10747 & 2425 \\
\hline Protein (\% energy) & $15 \cdot 6$ & 3.5 & $14 \cdot 8$ & $2 \cdot 7$ & $15 \cdot 6$ & 3.0 & $15 \cdot 6$ & 3.5 & $14 \cdot 2$ & 2.5 & 13.4 & 1.9 \\
\hline Carbohydrates (\% energy) & 49.4 & 5.4 & $49 \cdot 6$ & 5.4 & $49 \cdot 6$ & $5 \cdot 7$ & $48 \cdot 8$ & 4.9 & $51 \cdot 1$ & $5 \cdot 1$ & 51.6 & $6 \cdot 1$ \\
\hline Fat (\% energy) & $35 \cdot 0$ & 4.9 & $35 \cdot 6$ & $5 \cdot 2$ & 34.8 & 4.9 & $35 \cdot 6$ & $5 \cdot 3$ & $34 \cdot 7$ & 4.7 & 34.8 & 5.9 \\
\hline \multicolumn{13}{|l|}{ Hormonal status† } \\
\hline Leptin (ng/ml) & $45 \cdot 6$ & 25.8 & $37 \cdot 3$ & $17 \cdot 7$ & $45 \cdot 1$ & $25 \cdot 6$ & 38.1 & $18 \cdot 5$ & $29 \cdot 6$ & $28 \cdot 1$ & NA & \\
\hline $\mathrm{sObR}(\mathrm{ng} / \mathrm{ml})$ & 20.4 & 4.3 & $16 \cdot 8$ & 4.0 & $20 \cdot 2$ & 4.3 & $16 \cdot 3$ & 4.0 & $27 \cdot 7$ & $5 \cdot 2$ & NA & \\
\hline Leptin:sObR ratio & $2 \cdot 4$ & 1.4 & $2 \cdot 2$ & 0.8 & $2 \cdot 4$ & 1.3 & $2 \cdot 3$ & 0.8 & $1 \cdot 1$ & 1.0 & NA & \\
\hline Adiponectin $(\mu \mathrm{g} / \mathrm{ml})$ & $9 \cdot 3$ & $5 \cdot 1$ & 8.4 & $6 \cdot 6$ & $9 \cdot 8$ & $5 \cdot 1$ & $8 \cdot 8$ & $6 \cdot 7$ & $9 \cdot 7$ & $5 \cdot 6$ & NA & \\
\hline \multicolumn{13}{|l|}{ Anthropometry } \\
\hline Waist circumference $(\mathrm{cm})$ & 103.9 & 8.9 & $116 \cdot 0$ & 9.2 & 124.5 & $10 \cdot 2$ & 141.9 & $11 \cdot 2$ & $82 \cdot 1$ & $9 \cdot 7$ & $90 \cdot 1$ & 11.6 \\
\hline Hip circumference $(\mathrm{cm})$ & $119 \cdot 2$ & 7.6 & $114 \cdot 1$ & $6 \cdot 1$ & 139.1 & $12 \cdot 6$ & $137 \cdot 0$ & $10 \cdot 8$ & $102 \cdot 3$ & 7.9 & $100 \cdot 1$ & $9 \cdot 2$ \\
\hline Waist:hip ratio & 0.9 & 0.1 & 1.0 & 0.1 & 0.9 & 0.1 & 1.0 & 0.1 & 0.8 & 0.1 & 0.9 & 0.1 \\
\hline \multicolumn{13}{|l|}{ Skinfold thickness (mm) } \\
\hline Supraspinal skinfold & $26 \cdot 0$ & 7.9 & $23 \cdot 1$ & 8.8 & $30 \cdot 3$ & $12 \cdot 5$ & $32 \cdot 0$ & $16 \cdot 4$ & $19 \cdot 4$ & 24.4 & $15 \cdot 3$ & $5 \cdot 8$ \\
\hline Subscapular skinfold & $30 \cdot 1$ & 21.6 & 28.4 & 8.7 & 35.4 & $10 \cdot 0$ & $31 \cdot 0$ & $14 \cdot 6$ & $19 \cdot 1$ & $10 \cdot 6$ & 22.4 & 26.9 \\
\hline Biceptal skinfold & $22 \cdot 1$ & $6 \cdot 4$ & $16 \cdot 9$ & $5 \cdot 6$ & $26 \cdot 3$ & $8 \cdot 2$ & $25 \cdot 1$ & 8.0 & 14.5 & $5 \cdot 1$ & $11 \cdot 3$ & $6 \cdot 3$ \\
\hline Triceptal skinfold & $29 \cdot 6$ & 5.6 & $22 \cdot 9$ & $7 \cdot 0$ & 31.5 & $6 \cdot 9$ & $29 \cdot 1$ & 7.4 & 21.5 & 5.5 & $16 \cdot 5$ & $5 \cdot 3$ \\
\hline Sum of all skinfolds & $107 \cdot 7$ & 27.5 & $91 \cdot 3$ & $20 \cdot 0$ & $122 \cdot 8$ & $30 \cdot 3$ & $117 \cdot 2$ & 33.3 & $74 \cdot 2$ & 31.5 & 65.4 & $32 \cdot 8$ \\
\hline Systolic blood pressure (mmHg) & $135 \cdot 2$ & 19.5 & $141 \cdot 0$ & 17.5 & $140 \cdot 0$ & 24.7 & $140 \cdot 3$ & $17 \cdot 0$ & 121.9 & 17.9 & $125 \cdot 8$ & $12 \cdot 5$ \\
\hline Diastolic blood pressure (mmHg) & 89.0 & 11.0 & $92 \cdot 3$ & 13.6 & 93.1 & $17 \cdot 8$ & $95 \cdot 7$ & $12 \cdot 8$ & $81 \cdot 7$ & $11 \cdot 1$ & 79.7 & $11 \cdot 2$ \\
\hline
\end{tabular}

NA, not analysed.

† Analysed in a subset of individuals, consisting of the sixty-four morbidly obese subjects and sixty-four subjects from the other groups matched by age and sex. 
Table 2. Distributions of genotypes and alleles of examined polymorphisms in the studied subpopulations

\begin{tabular}{|c|c|c|c|c|c|c|c|}
\hline \multirow{3}{*}{$\begin{array}{l}\text { Polymorphism } \\
\text { ADIPOQ rs2241766 (+45T/G) (synonymous coding, GGT } \rightarrow \text { GGG, Gly } \rightarrow \text { Gly) } \\
\text { Obese cases }\end{array}$} & \multicolumn{4}{|c|}{ Genotypes } & \multicolumn{3}{|c|}{ Alleles } \\
\hline & TT & $\mathrm{TG}$ & $G G$ & $P$ & $\mathrm{~T}$ & $\mathrm{G}$ & $P$ \\
\hline & $149(81)$ & $28(15)$ & $7(4)$ & 0.36 & $326(89)$ & $42(11)$ & 0.42 \\
\hline Morbidly obese cases & $51(80)$ & $12(19)$ & $1(1)$ & 0.90 & $114(84)$ & $14(16)$ & 0.64 \\
\hline Controls & $126(82)$ & $25(16)$ & $2(2)$ & - & $277(91)$ & $29(9)$ & - \\
\hline ADIPOQ $+94 \mathrm{~T} / \mathrm{G}$ (synonymous coding, GGT $\rightarrow$ GGG, Gly $\rightarrow$ Gly) & TT & TG & GG & $P$ & $\mathrm{~T}$ & $\mathrm{G}$ & $P$ \\
\hline Obese cases & $97(61)$ & $45(28)$ & $16(11)$ & 0.26 & $239(76)$ & $77(24)$ & 0.74 \\
\hline Morbidly obese cases & $35(61)$ & 19 (33) & $3(6)$ & 0.96 & $89(78)$ & $25(22)$ & 0.79 \\
\hline Controls & $82(59)$ & $48(35)$ & $8(6)$ & - & $212(77)$ & $64(23)$ & - \\
\hline LEP rs2167270 (+19A/G) (5' UTR) & AA & AG & $\mathrm{GG}$ & $P$ & G & A & $P$ \\
\hline Obese cases & $73(40)$ & $84(46)$ & $24(14)$ & 0.66 & $230(63)$ & $132(37)$ & 0.85 \\
\hline Morbidly obese cases & $30(45)$ & $28(42)$ & $6(13)$ & 0.41 & $88(69)$ & $40(31)$ & 0.24 \\
\hline Controls & $58(37)$ & $80(52)$ & $18(11)$ & - & $196(63)$ & $116(37)$ & - \\
\hline LEPR rs1137101 (+27265A/G) (synonymous coding, CAG $\rightarrow$ CGG, Gln $\rightarrow$ Arg) & AA & $A G$ & GG & $P$ & A & G & $P$ \\
\hline Obese cases & $48(26)$ & $98(53)$ & $39(21)$ & 0.30 & $194(52)$ & $176(48)$ & 0.59 \\
\hline Morbidly obese cases & $20(31)$ & $33(51)$ & $12(18)$ & 0.66 & $77(57)$ & $57(43)$ & 0.75 \\
\hline Controls & $50(32)$ & $70(45)$ & $36(23)$ & - & $170(54)$ & $142(46)$ & - \\
\hline POMC rs3754860 (+1798C/T) (5' UTR) & ++ & +- & -- & $P$ & + & - & $P$ \\
\hline Obese cases & $76(41)$ & $90(49)$ & $19(10)$ & 0.68 & $242(65)$ & $128(35)$ & 0.40 \\
\hline Morbidly obese cases & $23(35)$ & $34(52)$ & $8(13)$ & 0.34 & $80(62)$ & $50(38)$ & $0 \cdot 16$ \\
\hline Controls & $71(45)$ & $73(46)$ & $13(9)$ & - & $215(69)$ & $99(31)$ & - \\
\hline POMC rs1009388 (+1032C/G) (intronic) & $\mathrm{CC}$ & CG & $\mathrm{GG}$ & $P$ & C & G & $P$ \\
\hline Obese cases & $111(59)$ & $64(34)$ & $12(7)$ & 0.75 & $286(76)$ & $88(24)$ & 0.89 \\
\hline Morbidly obese cases & $40(62)$ & $21(32)$ & $4(6)$ & 0.91 & $101(78)$ & $29(22)$ & 0.86 \\
\hline Controls & $96(62)$ & $48(31)$ & $12(7)$ & - & $240(77)$ & $72(23)$ & - \\
\hline IL-6 rs1800797 (-596A/G) (5' UTR) & GG & GA & AA & $P$ & G & A & $P$ \\
\hline Obese cases & $56(32)$ & $90(51)$ & $31(17)$ & 0.94 & $202(57)$ & $152(43)$ & 0.75 \\
\hline Morbidly obese cases & $22(34)$ & $28(44)$ & $14(22)$ & 0.54 & $72(56)$ & $56(44)$ & 0.94 \\
\hline Controls & $46(30)$ & $80(52)$ & $28(18)$ & - & $172(56)$ & $136(44)$ & - \\
\hline IL-6 rs1800795 (-174G/C) (5' UTR) & $\mathrm{CC}$ & CG & GG & $P$ & C & $G$ & $P$ \\
\hline Obese cases & $54(31)$ & $92(52)$ & $30(17)$ & 0.88 & $200(57)$ & $152(43)$ & 0.67 \\
\hline Morbidly obese cases & $20(31)$ & $30(47)$ & $14(22)$ & 0.82 & $70(55)$ & $58(45)$ & 0.93 \\
\hline Controls & $43(30)$ & $75(51)$ & $28(19)$ & - & $161(55)$ & $131(45)$ & - \\
\hline
\end{tabular}

ADIPOQ, adiponectin; LEP, leptin; UTR, untranslated region; LEPR, leptin receptor; POMC, pro-opiomelanocortin.

*Numbers in parentheses are the percentages of the genotypes present in the different groups. For some genotypes, only a $83-90 \%$ success rate could be reached due to a less efficient PCR amplification. 
Table 3. Association between the upper and lower tertiles of extreme snacking behaviour with obesity in the studied cohorts

\begin{tabular}{|c|c|c|c|c|c|c|c|}
\hline & \multicolumn{2}{|c|}{ Obesity $(+)$} & \multicolumn{2}{|c|}{ Obesity $(-)$} & \multirow[b]{2}{*}{ OR } & \multirow[b]{2}{*}{$95 \% \mathrm{Cl}$} & \multirow[b]{2}{*}{$P$} \\
\hline & $\%$ & Total $n$ & $\%$ & $\overline{\text { Total } n}$ & & & \\
\hline Total & & & & & 0.57 & $0.35,0.95$ & $0.019^{*}$ \\
\hline Upper tertile & 75 & 248 & 59 & 155 & & & \\
\hline Lower tertile & 93 & 248 & 42 & 155 & & & \\
\hline Male & & & & & 1.26 & $0.42,3.74$ & 0.44 \\
\hline Upper tertile & 13 & 61 & 7 & 36 & & & \\
\hline Lower tertile & 28 & 61 & 19 & 36 & & & \\
\hline Female & & & & & 0.42 & $0.23,0.77$ & $0.003^{*}$ \\
\hline Upper tertile & 62 & 187 & 52 & 119 & & & \\
\hline Lower tertile & 65 & 187 & 23 & 119 & & & \\
\hline
\end{tabular}

${ }^{*} P<0.05$.

$P=0 \cdot 02)$. In the multivariate modelling adjusted for age, sex and smoking, the LEPR Gln223Arg polymorphism was positively correlated with the energy value of the dinner ( $\beta=0.13 ; P=0.04)$, whereas the GG carriers expressed a trend toward higher energy intake later on, in their dinner. Moreover, the LEP $+19 \mathrm{~A} / \mathrm{G}$ polymorphism was correlated with the energy value of the supper $(\beta=0.13 ; P=0.05)$, with the AG heterozygotes expressing a tendency toward the highest energy intake in their supper.

In the above-defined subset of patients, LEP, sObR and ADIPOQ plasma levels were analysed in relation to examined SNP. Neither ADIPOQ $+45 \mathrm{~T} / \mathrm{G}$ nor $+94 \mathrm{~T} / \mathrm{G}$ was associated with ADIPOQ plasma levels either in the obese or lean individuals. The LEPR Gln223Arg polymorphism was correlated with the ADIPOQ plasma levels ( $\beta=-0.28 ; P=0.03)$, whereas the GG homozygotes were showing on average the lowest plasma ADIPOQ levels. The Rsa I polymorphism was associated with both plasma LEP levels $(P=0.007)$ and the LEP:sObR ratio $(P=0.003)$. Furthermore, the bivariate analysis was performed on examined polymorphisms to assess possible associations of LEP, sObR and the LEP:sObR ratio or ADIPOQ and dietary characteristics. To control for possible confounders, the results from the bivariate correlation analysis were consecutively explored using multivariate analysis using logarithmically transformed plasma LEP and sObR and LEP: sObR ratio regressed on total energy intake as well as on the energy intake provide by each macronutrient ${ }^{(19)}$. However, no significant associations were observed.

In a separate analysis, sObR plasma levels and the LEP: sObR ratio were significantly correlated with systolic blood pressure $(\beta=-0.66, P=0.002 ; \beta=-1.23, P=0.02)$ and sObR plasma levels also served as an independent predictor for diastolic blood pressure $(\beta=-0 \cdot 50 ; P=0 \cdot 04)$.

\section{Discussion}

The investigation of genotype $\times$ nutrient interactions is a general base for a better understanding of the multifactorial pathogenesis of complex diseases as well as for the identification of obesity-related traits. Unfortunately, the evaluation of genotype $\times$ nutrient associations seems to be extremely difficult, mainly because of the complicated epidemiology of obesity, too many candidate genes investigated and also because of the small power of the reported observed findings, altogether making the investigation of genotype $\times$ food preferences highly tangled and difficult to accomplish ${ }^{(16)}$.

In the present study, we investigated the associations of eight SNP in adipose tissue-related genes in a cohort of 409 individuals with precisely quantified anthropometric and dietary characteristics and we employed different statistical models to precisely assess interactions defined as departures from the multiplicative risk ratios ${ }^{(16)}$, thus strengthening our analysis.

The allele frequencies and genotype distributions within the present study closely resembled those previously reported in other Caucasian European populations ${ }^{(27-29)}$; no significant differences were observed both in allele and genotypes frequencies and these were highly similar to those reported for the HapMap CEU population (Utah residents with ancestry from northern and western Europe $)^{(30)}$.

Moreover, the results of the present study refer to the possible interaction between the carriers of the genetic variant of the LEP + 19A/G polymorphism and various anthropometric parameters including BMI, percentage body fat and skinfold thickness. Our findings are partially in accordance with the findings of Mizuta et al. ${ }^{(31)}$, as we did not observe any association of the LEP $+19 \mathrm{~A} / \mathrm{G}$ polymorphism with plasma LEP levels either; however, we did not confirm any associations of LEP + 19A/G or LEPR Gln223Arg with sweet preference described by these Japanese investigators.

Analysis of the anthropometric parameters revealed a significant association of ADIPOQ + 94T/G with subscapular skinfold thickness. As reported by Yang et al. ${ }^{(32)}$ the synonymous mutation ADIPOQ + 94T/G might affect steady-state mRNA levels by altering RNA splicing or stability ${ }^{(32)}$. This T/G or linked polymorphism nearby could therefore affect mRNA splicing or stability and lead to extensive metabolic consequences that might result in varying body fat distribution. The strong linkage disequilibrium with type 2 diabetes, measures of adiposity, and insulin levels found in the chromosomal region where the ADIPOQ gene is located $^{(33-34)}$ suggest that somewhere on this locus a common genetic variant should be located, such as the T-G polymorphism in the ADIPOQ gene, that expresses measurable effects on adiposity-related traits. As far as we know, the present study is the first to report an association of ADIPOQ + 94T/G with skinfold thickness. 
Moreover, we observed a significant effect of the '- , allele of the POMC Rsa I polymorphism on the percentage of body fat, where the ' - _ ' homozygotes presented with the highest percentage of body fat when compared with the ' + ' allele carriers. This is in contrast to the study by Baker et al. ${ }^{(22)}$ who did not observe any effects of Rsa I on BMI or waist:hip ratio; moreover, we did not observe the association of the POMC C1032G polymorphism with the waist:hip ratio or BMI reported by these authors.

Surprisingly, the tertile analysis of the macronutrient intake revealed that the presence of extreme snacking behaviour was in the total studied cohort (obese cases plus non-obese individuals) associated with lower obesity risk, which contradicts the generally accepted model of maintaining steady body weight. The present results are in accordance with a study by Lioret et al. ${ }^{\left({ }^{35)}\right.}$ on 748 French children, as the authors concluded that a combination of more frequent food intake occasions and lower contribution of the main meals to total daily energy intake is associated with a smaller risk of overweight in children. However, the observed patterns were not consistently expressed in males in the present study and thus conclusions on these eating patterns in relation to obesity risk require further investigation, possibly with a prospective design.

Furthermore, significant interactions with various dietary and circadian characteristics concerning the LEPR Gln223Arg polymorphism were observed. Recently, it has been reported by Guízar-Mendoza et al. ${ }^{(36)}$ that adolescent individuals with the $\mathrm{A}$ allele $(\mathrm{A} / \mathrm{A}$ and $\mathrm{A} / \mathrm{G})$ had higher heart sympathetic activity, body fat percentage and LEP levels. This is partially in contrast to our findings of higher plasma LEP levels in $G$ allele carriers $(\mathrm{GG}+\mathrm{GA})$, also observed in our previous study ${ }^{(17)}$; however, the $\mathrm{G}$ allele carriers in the present study presented with lower body fat percentage, which is in accordance with the Mexican adolescent cohort. The finding of half the risk of AA carriers for diastolic blood pressure in our cohort is also in contrast to this Mexican study, where a sympathetic effect of the A allele was observed. The present study is so far the first to demonstrate any effect of LEPR Gln223Arg on the structuring of energy intake during the day, and thus it provides a basis for further investigation of the possible association of Gln223Arg with eating behaviour and involvement of this polymorphism in the regulation of circadian rhythmicity. In this context, the observed significant association of the LEPR Gln223Arg polymorphism with the blood pressure values is of particular importance.

We did not confirm the observations by Yannakoulia et al. ${ }^{(19)}$ that the sObR is positively associated with energy intake from carbohydrates and negatively with energy intake from dietary fat, whereas the free LEP index was in this study on a Greek population negatively associated with energy intake from carbohydrates and positively with energy intake from dietary fat, thus contrasting with the present results. The present study also did not reveal any associations of free LEP and sObR with energy intake and the macronutrient composition of the diet reported by Yannakoulia et al. ${ }^{(19)}$.

The main strength of the present study is the use of stateof-the-art methodology including $7 \mathrm{~d}$ food records for evaluating the subjects' dietary intake. The $7 \mathrm{~d}$ food records provide quantitatively accurate information on food consumed during the recording period by recording food while it is consumed, the problem of reporting bias or omission is lessened, whereas subjects are not restricted to selecting from a predetermined list of foods included in a FFQ ${ }^{(19)}$. Although confounding was appropriately controlled for through standard statistical procedures, there is always a possibility of residual confounding by other serum adipokines, genetic factors or unmeasured and unknown factors that have to be considered. Confirmation of the present results by future studies on different populations and above all the precise assessment of the adipokine genes in relation to the time structure of daily energy intake are warranted.

To conclude, the present population-based case-control study revealed significant associations of selected polymorphisms in genes encoding for adipokines both with percentage body fat, skinfold thickness and specific dietary composition and time patterns of feeding behaviour.

\section{Acknowledgements}

Each author has made an important scientific contribution to the study and has assisted with the drafting or revising of the manuscript, in accordance with the definition of an author as stated by the International Committee of Medical Journal Editors.

The present study was supported by the Ministry of Education of the Czech Republic (grant no. 881/2006) and by a project of the Danone Institute of the Czech Republic (DANONE/2007) focused on genetic variability of adipokines in obese individuals.

The authors are grateful to Dana Polášková, Petra Přikrylová, Svatava Tschoplová and Jarmila Laušová for technical assistance. We thank Kateřina Heczková, Zlata Piskáčková and Lenka Kučerová for their assistance in processing and analysing food records.

\section{References}

1. Marti A, Martinez-González MA \& Martinez JA (2008) Interaction between genes and lifestyle factors on obesity. Proc Nutr Soc 67, 1-8.

2. Uusitupa M (2005) Gene-diet interaction in relation to the prevention of obesity and type 2 diabetes: evidence from the Finnish Diabetes Prevention Study. Nutr Metab Cardiovasc Dis 15, 225-233.

3. Kenchaiah S, Evans JC, Levy D, et al. (2002) Obesity and the risk of heart failure. $N$ Engl J Med 347, 305-313.

4. Sharma AM \& Chetty VT (2005) Obesity, hypertension and insulin resistance. Acta Diabetol 42, S3-S8.

5. Barsh GS, Farooqi IS \& O'Rahilly S (2000) Genetics of bodyweight regulation. Nature 404, 644-651.

6. Clément K, Vaisse C, Lahlou N, et al. (1998) A mutation in the human leptin receptor gene causes obesity and pituitary dysfunction. Nature 392, 398-401.

7. Farooqi IS, Wangensteen T, Collins S, et al. (2007) Clinical and molecular genetic spectrum of congenital deficiency of the leptin receptor. $N$ Engl J Med 356, 237-247.

8. Krude H, Biebermann H, Luck W, et al. (1998) Severe earlyonset obesity, adrenal insufficiency and red hair pigmentation caused by POMC mutations in humans. Nat Genet 19, 155-157.

9. Yiannakouris N, Melistas L, Yannakoulia M, et al. (2003) The $-2548 \mathrm{G} / \mathrm{A}$ polymorphism in the human leptin gene 
promoter region is associated with plasma free leptin levels; interaction with adiposity and gender in healthy subjects. Hormones 2, 229-236.

10. Vivenza D, Rapa A, Castellino N, et al. (2004) Ghrelin gene polymorphisms and ghrelin, insulin, IGF-I, leptin and anthropometric data in children and adolescents. Eur J Endocrinol 151, 127-133.

11. Portolés O, Sorlí JV, Francés F, et al. (2006) Effect of genetic variation in the leptin gene promoter and the leptin receptor gene on obesity risk in a population-based case-control study in Spain. Eur J Epidemiol 21, 605-612.

12. Chagnon YC, Wilmore JH, Borecki IB, et al. (2000) Associations between the leptin receptor gene and adiposity in middle-aged Caucasian males from the HERITAGE family study. J Clin Endocrinol Metab 85, 29-34.

13. Slattery ML, Curtin K, Sweeney C, et al. (2008) Modifying effects of IL-6 polymorphisms on body size-associated breast cancer risk. Obesity 16, 339-347.

14. de Krom M, van der Schouw YT, Hendriks J, et al. (2007) Common genetic variations in CCK, leptin, and leptin receptor genes are associated with specific human eating patterns. Diabetes 56, 276-280.

15. Schulz LO, Bennett PH, Ravussin E, et al. (2006) Effects of traditional and Western environments on prevalence of type 2 diabetes in Pima Indians in Mexico and the U.S. Diabetes Care 29, 1866-1871.

16. Santos JL, Boutin P, Verdich C, et al. (2006) Genotype-bynutrient interactions assessed in European obese women. A case-only study. Eur J Nutr 45, 454-462.

17. Bienertova-Vasku J, Bienert P, Tomandl J, et al. (2008) No association of defined variability in leptin, leptin receptor, adiponectin, proopiomelanocortin and ghrelin gene with food preferences in the Czech population. Nutr Neurosci 11, 2-8.

18. Ma Y, Bertone ER, Stanek EJ III, et al. (2003) Association between eating patterns and obesity in a free-living US adult population. Am J Epidemiol 158, 85-92.

19. Yannakoulia M, Yiannakouris N, Bluher S, et al. (2003) Body fat mass and macronutrient intake in relation to circulating soluble leptin receptor, free leptin index, adiponectin, and resistin concentrations in healthy humans. J Clin Endocrinol Metab 88, 730-736.

20. Mammès O, Betoulle D, Aubert R, et al. (2000) Association of the G-2548A polymorphism in the $5^{\prime}$ region of the LEP gene with overweight. Ann Hum Genet 64, 391-394.

21. Gaukrodger N, Mayosi BM, Imrie H, et al. (2005) A rare variant of the leptin gene has large effects on blood pressure and carotid intima-medial thickness: a study of 1428 individuals in 248 families. J Med Genet 42, 474-478.

22. Baker M, Gaukrodger N, Mayosi BM, et al. (2005) Association between common polymorphisms of the proopiomelanocortin gene and body fat distribution: a family study. Diabetes 54, 2492-2496.
23. Monteleone P, Tortorella A, Castaldo E, et al. (2006) No association of the Arg51Gln and Leu72Met polymorphisms of the ghrelin gene with anorexia nervosa or bulimia nervosa. Neurosci Lett 398, 325-327.

24. Yang WS, Hsiung CA, Ho LT, et al. (2003) Genetic epistasis of adiponectin and PPAR $\gamma 2$ genotypes in modulation of insulin sensitivity: a family-based association study. Diabetologia 46, 977-983.

25. Nakatani K, Noma K, Nishioka J, et al. (2005) Adiponectin gene variation associates with the increasing risk of type 2 diabetes in non-diabetic Japanese subjects. Int J Mol Med 15, 173-177.

26. Rosmond R, Chagnon M, Bouchard C, et al. (2001) A missense mutation in the human melanocortin-4 receptor gene in relation to abdominal obesity and salivary cortisol. Diabetologia 44, $1335-1338$.

27. Pollin TI, Tanner K, O'Connell JR, et al. (2005) Linkage of plasma adiponectin levels to 3q27 explained by association with variation in the APM1 gene. Diabetes 54, 268-274.

28. Souren NY, Paulussen AD, Steyls A, et al. (2008) Common SNPs in LEP and LEPR associated with birth weight and type 2 diabetes-related metabolic risk factors in twins. Int J Obes (Lond) 32, 1233-1239.

29. Kämäräinen OP, Solovieva S, Vehmas T, et al. (2008) Common interleukin-6 promoter variants associate with the more severe forms of distal interphalangeal osteoarthritis. Arthritis Res Ther 10, R21.

30. International HapMap Consortium (2005) A haplotype map of the human genome. Nature 437, 1299-1320.

31. Mizuta E, Kokubo Y, Yamanaka I, et al. (2008) Leptin gene and leptin receptor gene polymorphisms are associated with sweet preference and obesity. Hypertens Res 31, 1068-1077.

32. Yang WS, Tsou PL, Lee WJ, et al. (2003) Allele-specific differential expression of a common adiponectin gene polymorphism related to obesity. J Mol Med 81, 428-434.

33. Kissebah AH, Sonnenberg GE, Myklebust J, et al. (2000) Quantitative trait loci on chromosomes 3 and 17 influence phenotypes of the metabolic syndrome. Proc Natl Acad Sci U S A 97, 14478-14483.

34. Vionnet N, Hani E, Dupont S, et al. (2000) Genomewide search for type 2 diabetes-susceptibility genes in French whites: evidence for a novel susceptibility locus for early onset diabetes on chromosome 3q27-qter and independent replication of a type 2-diabetes locus on chromosome 1q21-q24. Am J Hum Genet 67, 1470-1480.

35. Lioret S, Touvier M, Lafay L, et al. (2008) Are eating occasions and their energy content related to child overweight and socioeconomic status? Obesity (Silver Spring) 16, 2518-2523.

36. Guízar-Mendoza JM, Amador-Licona N, Flores-Martínez SE, et al. (2005) Association analysis of the Gln223Arg polymorphism in the human leptin receptor gene, and traits related to obesity in Mexican adolescents. J Hum Hypertens 19, 341-346. 